\title{
(2) OPEN ACCESS \\ Lethal hyperammonemia in a CAR-T cell recipient due to Ureaplasma pneumonia: a case report of a unique severe complication
}

\author{
Pierre Tawfik ํ), Patrick Arndt
}

Pulmonary, Allergy, Critical Care and Sleep Medicine, University of Minnesota Medical School Twin Cities, Minneapolis, Minnesota, USA

\section{Correspondence to} Dr Pierre Tawfik: pierretawfik@gmail.com

Accepted 11 June 2021

Check for updates

(c) BMJ Publishing Group Limited 2021. Re-use permitted under CC BY-NC. No commercial re-use. See rights and permissions. Published by BMJ.

To cite: Tawfik $P$, Arndt P. BMJ Case Rep 2021:14:e242513. doi:10.1136/bcr-2021242513

\section{SUMMARY}

We report the first incidence of Ureaplasma infection causing lethal hyperammonemia in a chimeric receptor antigen T cell (CAR-T) recipient. A 53-yearold woman, after receiving CAR-T therapy, suffered sepsis and encephalopathy. She was found to have hyperammonemia up to $643 \mu \mathrm{mol} / \mathrm{L}$. Imaging revealed lung consolidations and bronchoalveolar lavage PCR was positive for U. parvum. Workup excluded liver failure and metabolic abnormalities. Antibiotics, lactulose, dextrose, arginine, levocarnitine, sodium phenylbutyrate and dialysis were used. Despite these, the patient suffered persistent elevations in ammonia, status epilepticus and cerebral oedema. Early recognition of this rare infection in susceptible populations is needed. CAR-T patients are at risk due to their immunocompromised state and may have amplified harm due to the impact of CAR-T therapy on astrocytes. An early aggressive multimodality approach is needed given the high mortality rates. These include antimicrobials, possibly with double coverage for Ureaplasma. Additionally, concurrent ammoniasuppressing and ammonia-eliminating treatments are necessary.

\section{BACKGROUND}

Chimeric receptor antigen $\mathrm{T}$ cells (CAR-T) are a tumour-targeted immunotherapy with promising efficacy in relapsing haematological malignancies. In addition to treatment of haematological malignancies, trials are likewise underway for solid tumours. ${ }^{12}$ Complications of CAR-T therapy include neurotoxicities, the pro-inflammatory cytokine release syndrome (CRS) which has varying degrees of severity and can result in shock and multiorgan failure, and infectious complications due to the immunocompromised status of patients. ${ }^{3-5}$

One of the rare diseases in immunosuppressed populations is infection by urease-producing organisms (ie, Ureaplasma). These organisms can cause hyperammonemia. This has been described in patients on immunosuppressants for rheumatological conditions or during high-dose chemotherapy. ${ }^{67}$ More prevalent are reports of this phenomenon in transplant patients. Examples include solid organ transplant such as liver and kidney with lung transplantation noted as a unique risk factor for these infections, occurring in up to $4.1 \%$ of lung transplant recipients. ${ }^{89}$ The lung transplant literature has consequently provided a major source of reports for this phenomenon. Mortality is high in lung transplant patients with Ureaplasma infection, ranging from $50 \%$ to $75 \%$, even with early institutions of multimodality treatments. ${ }^{10}$ In addition to solid organ recipients, patients who have undergone stem cell transplants are also at risk of developing hyperammonemia from urease-splitting organisms. In 1996, Davies et al reviewed 2358 bone marrow transplant (BMT) patients and found $12(0.5 \%)$ cases of hyperammonemia. They noted that 10 of the 12 patients $(83 \%)$ died from progressive encephalopathy despite dialysis and ammoniatrapping agents. ${ }^{11}$ However, no definitive link was drawn at that time with urease-producing organisms and the clinical finding of hyperammonemia. ${ }^{12}$ Eleven years after the report by Davies et al, Graetz et al reported a case of a BMT recipient with elevated ammonia and positive Ureaplasma PCR from a tracheal aspirate, suggesting the infection as a likely aetiology for the hyperammonemia. This patient was successfully treated with antibiotics and had resolution of their hyperammonemia. ${ }^{13}$

In this report, we detail a case of hyperammonemia secondary to Ureaplasma in a patient who underwent CAR-T therapy. To our knowledge, no such case has been reported in CAR-T recipients.

\section{CASE PRESENTATION}

A 53-year-old Caucasian woman underwent a myeloablative allogeneic hematopoietic cell transplant for relapsing acute lymphoblastic leukaemia then suffered a relapse. Eleven months after BMT, she received CAR-T therapy targeting CD19. CAR-T lymphodepleting chemotherapy consisted of cyclophosphamide and fludarabine. Her subsequent course was complicated by grade 1 CRS requiring one dose of tocilizumab, one dose of methylprednisolone $(50 \mathrm{mg})$ and 7 days of prophylactic levetiracetam which was stopped due to improved neurotoxicity (confusion).

Two weeks after CAR-T therapy, she was admitted to the ward with ongoing pancytopenia, fevers and Escherichia coli bacteraemia which was successfully treated. She then developed new fevers, dyspnoea and hypoxemia requiring $2 \mathrm{~L}$ of continuous oxygen via nasal cannula. CT imaging of the chest revealed consolidations in the right upper, right middle and left upper lobes (figure 1). Blood cultures revealed new vancomycin-resistant enterococcal bacteraemia. She was on prophylactic foscarnet, pentamidine, isavuconazole and levofloxacin at that time which were broadened to meropenem and linezolid. The following day, she developed 


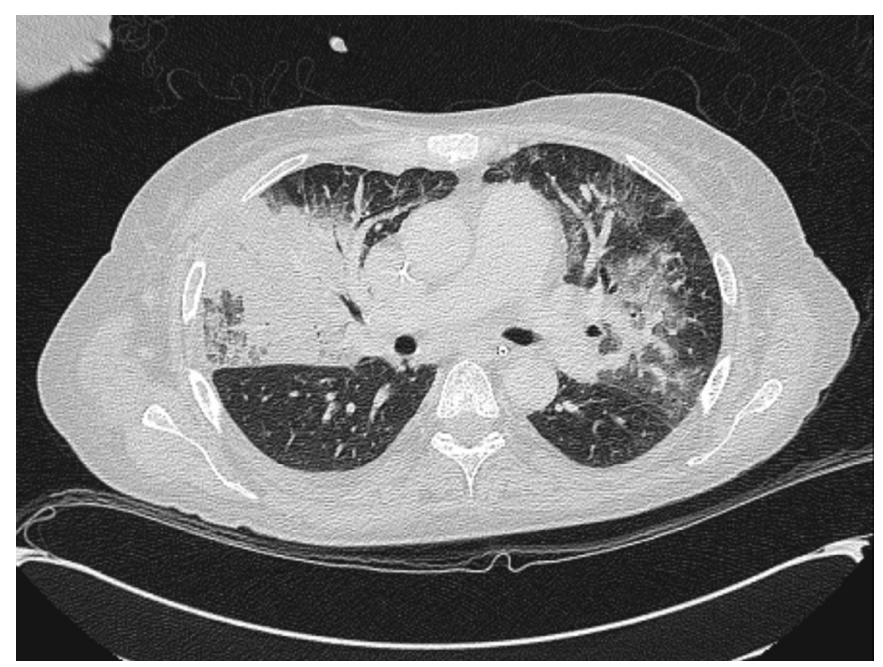

Figure 1 Axial non-contrast chest CT showing consolidation and ground-glass opacities in the right upper, right middle and left upper lobe.

restlessness, agitation then obtundation which prompted intubation and intensive care unit (ICU) transfer.

\section{INVESTIGATIONS AND TREATMENT}

A basic metabolic panel was normal. The patient had intermittently mild elevation of the total bilirubin ranging from 1.0 to $2.2 \mathrm{mg} / \mathrm{dL}$ (normal range $0.2-1.3 \mathrm{mg} / \mathrm{dL}$ ) and a minor increased international normalised ratio (INR) ranging from 1.15 to 1.54 $\mathrm{mg} / \mathrm{dL}$ (normal range $0.86-1.14 \mathrm{mg} / \mathrm{dL}$ ), thought due to malnutrition. She maintained normal kidney function and a blood urea nitrogen (BUN) level between 8 and $14 \mathrm{mg} / \mathrm{dL}$ (normal range 7-30 mg/dL) throughout the admission. A complete blood count showed ongoing pancytopenia with white blood cells (WBCs) $0.0 \times 10^{9} / \mathrm{L}$ (normal range $4.0-11.0 \times 10^{9} / \mathrm{L}$ ), haemoglobin of $6.7 \mathrm{~g} / \mathrm{dL}$ (normal range $11.7-15.7 \mathrm{~g} / \mathrm{dL}$ ) and platelet count of $16 \times 10^{9} / \mathrm{L}$ (normal range $150-450 \times 10^{9} / \mathrm{L}$ ) .

Encephalopathy workup was initiated on the first day of ICU admission. This included normal thyroid-stimulating hormone, vitamin $B_{1}$ and vitamin $B_{12}$ levels. An electroencephalogram was negative for epileptiform activity. Additionally, a head CT was negative for acute findings. A lumbar puncture revealed $0 \mathrm{WBC}$ (normal range 0-5), 0 red blood cell (RBC) (normal range 0-2), protein was $21 \mathrm{mg} / \mathrm{dL}$ (normal range 15-60 mg/dL), and the glucose level was $82 \mathrm{mg} / \mathrm{dL}$ (normal range $40-70 \mathrm{mg} / \mathrm{dL}$ ). Cerebrospinal fluid obtained during the lumbar puncture was sent for gram stain, bacterial culture, fungal culture, herpes simplex virus PCR, cytomegalovirus PCR, varicella zoster virus PCR, cryptococcal antigen, cytology and flow analysis for leukaemia and lymphoma; all of which were negative.

An ammonia level was checked and was $391 \mu \mathrm{mol} / \mathrm{L}$ (normal range $10-50 \mu \mathrm{mol} / \mathrm{L}$; the level was $39 \mu \mathrm{mol} / \mathrm{L} 2$ weeks prior). Figure 2 outlines the patient's subsequent ammonia levels and medical interventions. CT imaging of the patient's abdomen and pelvis and ultrasound imaging of the patient's abdomen with Doppler flows showed ongoing anasarca, due to hypoalbuminaemia, but no cirrhosis or obstruction of the patient's portal venous, hepatic venous or hepatic arterial systems. Doxycycline was therefore added to cover for ammonia-producing organisms given our centre's experience with this complication in lung transplantation. Oral lactulose was started. One gram of methylprednisolone per day was also provided for CRS treatment.

Bronchoscopy with bronchoalveolar lavage (BAL) was performed on ICU day \# 1 and sent for bacterial, fungal and viral cultures, PCR and staining. The cell count from the BAL fluid was $254 \mathrm{WBCs} / \mu \mathrm{L}$ (2\% lymphocytes, $98 \%$ other cells including monocytes, macrophages and epithelial cells). Ureaplasma PCR was sent from the BAL fluid.

On the second day of ICU admission, the patient's ammonia rose to $643 \mu \mathrm{mol} / \mathrm{L}$. Electroencephalography concurrently revealed epileptiform activity that was unrelenting despite highdose benzodiazepine infusion, levetiracetam, lacosamide and propofol infusion. Pentobarbital was then initiated and halted her status epilepticus. Repeat CT imaging of the head showed mildly diminished gray-white differentiation concerning for mild cerebral oedema. Renal replacement therapy was started for ammonia clearance with initial reduction in levels to 258 $\mu \mathrm{mol} / \mathrm{L}$, but no further decline. The patient's meropenem was changed to ceftazidime/avibactam. Amphotericin B and acyclovir were also added for further empirical coverage.

On the 3 rd and 4th days of ICU admission, a genetics consult was obtained for hyperammonemia to assess for inborn errors of metabolism. Workup, however, including urine organic acids,

Figure 2 Timeline demonstrating ammonia levels (in $\mu \mathrm{mol} / \mathrm{L}$ ) throughout the patient's course and the treatment interventions that were attempted to reduce the hyperammonemia. ICU, intensive care unit. 
urine orotic acid, plasma amino acids and plasma acylcarnitine levels, were negative. Genetics testing on a stored bone marrow sample demonstrated no chromosomal abnormalities. Intravenous infusions were adjusted to include dextrose, and dextrose $10 \%$ infusion was started to lower the patient's protein metabolic load. Levocarnitine, arginine infusion and sodium phenylbutyrate were sequentially added but ammonia levels did not decline below $270 \mu \mathrm{mol} / \mathrm{L}$.

\section{OUTCOME}

MRI of the brain was obtained on the 5th day of ICU admission, which showed diffuse worsening of the cerebral oedema. The Ureaplasma PCR from the BAL fluid returned positive, and levofloxacin was added for additional Ureaplasma coverage. However, given the progression in brain damage on imaging, the patient's family elected to withdraw care and the patient died.

\section{DISCUSSION}

Ammonia is a typical metabolite in the human body. However, elevated levels can cause severe neurological damage and mortality. Hyperammonemia is typically caused by cirrhosis in adults and by inborn errors of metabolism in children. ${ }^{14}$ The majority of circulating ammonia is produced in the intestines due to protein digestion. Skeletal muscle and the kidneys both produce and eliminate ammonia. Ammonia that is produced in the gut, or in excess from skeletal muscle or the kidneys, is metabolised in the liver. In hepatocytes, the ammonia enters the urea cycle which produces urea. It can also be converted to glutamine via glutamine synthase. The urea cycle uses several enzymes including phosphate synthetase, ornithine transcarbamylase, argininosuccinate synthetase and arginiase. Arginine is thus a necessary amino acid for the urea cycle and becomes essential in the treatment of urea cycle defects. ${ }^{15}$ Urea is then excreted in the kidneys. ${ }^{16}$ Accordingly, hepatic dysfunction or enzymatic defects result in an increase in serum ammonia levels.

In addition to the normally produced endogenous ammonia, infections by urease-positive organisms can also produce ammonia, thereby significantly raising blood levels. ${ }^{17}$ Ureaplasma and Mycoplasma are members of the bacterial family Mycoplasmataceae, which characteristically lacks a cell wall. All members of the Ureaplasma genus possess urease, which breaks down urea and produces ammonia. ${ }^{18}$ Ureaplasma commonly colonises the urogenital tract where it has been implicated in a breadth of urogenital diseases such as urethritis, male infertility and chorioamnionitis. ${ }^{1718}$ In contrast to the urogenital tract, Ureaplasma is not a typical part of the lung microbiome. It has been described as a cause of bronchopulmonary dysplasia in infants, pneumonitis in immunocompromised children and pneumonia in lung transplant patients. ${ }^{171920}$ Detection of these organisms with culture is difficult as it requires a Mycoplasma-specific media culture with incubation over 2-5 days. PCR testing is alternatively available and is a more practical approach. ${ }^{18}$ Ureaplasma is typically susceptible to macrolides, tetracyclines and fluoroquinolones but resistant to beta-lactam antibiotics given their lack of a cell wall. ${ }^{17} 18$

Our patient suffered lethal complications of hyperammonemia with ammonia levels remaining elevated despite multiple therapies. Exploring the possible explanations, along with mechanisms for hyperammonemia in similar patients, may inform treatment for future incidents. Multiple mechanisms have been postulated for hyperammonemia in transplant patients. One hypothesis is a lack of glutamine synthase or urea cycle enzymes. This has been shown in some lung transplant patients, but not consistently among all cases. ${ }^{10}$ Other hypotheses implicate calcineurin inhibitors and steroids as inhibitors of ammonia metabolism in skeletal muscle. ${ }^{10}$ Our patient was on neither of these medications.

Urease-producing organisms have now been shown to play a major role in raising ammonia levels in susceptible populations. ${ }^{6}$ 8-10 1319 Our patient may have had a particularly high infectious burden evidenced by bilateral lung consolidations, with BAL samples returning positive only for Ureaplasma. The patient was immunosuppressed throughout her last year of life, since the BMT, and likely acquired the Ureaplasma infection during this period of time. Ureaplasma itself creates a dangerous cycle of self-proliferation. The organism uses urea for energy, thus producing ammonia. The ammonia is then a substrate for further ureagenesis. This cycle results in a growing burden of infection. ${ }^{10}$ Our patient may have also had mild hepatic dysfunction, evidenced by mild bilirubin and INR elevations. The lack of BUN elevation, despite the severe ammonia levels, is further suggestive of a disruption in the urea cycle. This may be due to CRS or liver dysfunction from sepsis. ${ }^{21}$ The patient additionally had severe neurotoxicity, evidenced by status epilepticus that was very difficult to suppress, as well as cerebral oedema. This degree of neurological severity seen in our patient was potentially linked to CAR-T's impact on astrocytes. Gust et al reviewed 19 cases of neurotoxicity in CAR-T patients. They found multiple biomarkers in cerebrospinal fluid indicating astrocyte damage. ${ }^{22}$ Ammonia is taken up by astrocytes in the brain and converted to glutamine, with elevated levels of glutamine then causing cerebral oedema. Impairment of astrocytes, possibly due to CAR-T therapy, triggers excessive astrocyte activity in adjacent regions. This leads to increased glutamate concentrations in these nearby synapses. ${ }^{15}$ The overall impact of this physiology is increased excitotoxicity leading to encephalopathy and seizures. Brain herniation can also occur. ${ }^{15}$ Thus, CAR-T therapy may directly impact astrocytes, further potentiating the severity of hyperammonemia in our patient.

Making a diagnosis of hyperammonemia due to ureaseproducing organisms is challenging in the CAR-T population. Acute encephalopathy could be due to sepsis or CAR-T therapy itself among other aetiologies. However, elevated ammonia in the setting of normal or near-normal hepatic function is a helpful clue. Given the patient's age, an undiagnosed inborn error of metabolism was also unlikely. However, it cannot be entirely excluded by age and a genetics evaluation should always be pursued in these patients without delaying other treatments. Finally, one must recognise that regular cultures will not detect these organisms and PCR testing is needed to diagnose the infection. $^{23} 24$

Given the high mortality rate in these populations, we advocate for early empirical coverage for urea-producing organisms in immunocompromised populations with hyperammonemia without evidence of liver disease. Some prior reports have demonstrated successful treatment by following this treatment pathway. Graetz et al reported improved ammonia levels in a BMT patient with Ureaplasma and Legouy et al presented a successfully treated case in a renal transplant patient. ${ }^{9}{ }^{13}$ In the first case, levofloxacin plus azithromycin were used initially followed by levofloxacin alone. In the latter case, levofloxacin plus doxycycline were used. Although double coverage is not commonly recommended, the success in these cases in lowering ammonia compared with our patient is notable. ${ }^{17} 18$ Given the immunocompromised state of these populations, early double coverage with a macrolide and fluoroquinolone may be necessary to achieve infection control. 
Patient's perspective

My sister was diagnosed with ALL leukemia in March of 2019 after almost a year of being in and out of the hospital she was finally able to do the stem cell transplant in February 2020. We were so hopeful that this would be the answer to our prayers and put her into remission. Several months later (July) we learned that the transplant did not take and that the leukemia was again present. We were then told her only hope would be a CAR-T cell trial or remain on the inotuzumab which was keeping the leukemia at bay but they told us that would only work for so long. I'm not sure the timeline but I know she wasn't able to do another stem cell transplant for a certain amount of time so she decided on the CAR-T cell therapy. They say hindsight is 50/50 right?!....well now I wish she wouldn't have done the CAR-T cell therapy and remained on the inotuzumab. However I know her concern was that the trials are only offered periodically so she was worried about not being one when and if the inotuzumab stopped working. She wanted to do everything she could to be here for her 15-year-old daughter.

The CAR-T cell trial was set for the beginning of November and at first everything seemed to be ok. She remained in the hospital for about a month and was finally allowed to go home. She was going into the clinic for daily checks and infusions and on the 3rd day she was feeling off before her appointment. She went to her appointment that day and never came back home. By that afternoon she had developed a fever and they transported her to the hospital. By that evening they had suspected she had sepsis and was in respiratory distress and was intubated by that evening. This was very scary for all us! Not only the fact that she was being intubated and put in the ICU but also the fact that they discovered she had sepsis and $E$. coli which we all knew both on their own can be deadly. Especially for someone who has no immune system due to the underlying treatments and conditions.

What happened from this point forward seemed like a roller coaster ride. A series of unfortunate events that ultimately led to her death. The first time she was in the ICU and on the ventilator was about for about a week. We were relieved when she came off the ventilator and finally came around. I was only able to talk to her one day (it was a Wednesday) and she sounded great but our conversation was cut short because a doctor had come into the room. From what I've been told this one of her only good days that week. At this point we all thought she was in the clear and we were hopeful once again. The sepsis and $E$. coli seemed to have been responding to treatment. She was super weak but we were told this was normal and she would regain her strength with time. I believe there was only a one week span between the two times she was in the ICU and on the ventilator.

Things took a turn for the worse a couple days after we spoke and she was no longer coherent. We were told her ammonia levels were high. Somewhere between Friday and Saturday we were told she had seizures due to the high ammonia levels that lasted several hours (4-5) and they had a hard time getting them under control. At this point they had put her back on the ventilator and transferred her back to the ICU. We were told they suspected some brain damage. At first we were hopeful because she had just made it through a week of being on the ventilator and in the ICU and came out ok but as the days went by the complications kept adding up and it seemed like all the cards were stacking against her. Later we did find out she had sustained brain damage from the seizures and possibly had a

Continued

\section{Patient's perspective Continued}

stroke. We were also told her ammonia levels were EXTREMELY high and that she would be put on dialysis to help lower the levels. Dialysis helped a little at first but then the ammonia levels went up again. We were also told that the high ammonia levels were most likely causing even more brain damage. There was mention of a strange infection in her lungs that is normally only seen in lung transplant patients (Ureaplasma) but this didn't seem to be the focus from our perspective. After reading the medical report it now seems the Ureaplasma is where this all stemmed from. We were told they were trying different antibiotics to help with the infection. Ultimately nothing that was being done seemed to help. Each day that went by we were losing hope. We were told day to day it's all in how her body reacts. Despite the dialysis and all the meds her ammonia levels started to rise again. We were told her heart was failing and they were now having to give her medication to raise her blood pressure in order to keep her heart beating. The final straw for us was hearing this and hearing the news of her most recent brain scan. We were told she was basically brain dead although those words were not used. The most heartbreaking part to all of this is the fact that we are living in a pandemic where no one was allowed into the hospital. We were not able to see her, hold her hand, kiss her or be there with her through any of this. In the end we decided to turn off the life support. My sister's wishes were to be able to live a sustainable life on her own, to walk, talk, eat, sleep and breathe on her own. It did not sound like this would ever happen again. We decided to stop life support and at first were told only two people could come say their goodbyes. After clearing it with the head nurse they let six of us in. Two at a time to say our goodbyes. My mother was too sick to come in and had to say her goodbyes on FaceTime. It was absolutely heartbreaking.

Additional treatment modalities for the management of hyperammonemia aim to reduce ammonia production or absorption, increase elimination and reduce neurological effects. Much of the literature stems from treatment of patients with inborn errors of metabolism or hepatic failure. ${ }^{25}$ To reduce absorption, lactulose and rifaximin are most commonly used. Lactulose acidifies the intestines causing a hostile environment for bacteria that produce ammonia. Lactulose's cathartic effect promotes gastrointestinal elimination of ammonia. Rifaximin is the preferred antibiotic agent given its broad antimicrobial activity in the intestines and minimal bioavailability. ${ }^{25}$ To reduce intestinal production, protein intake should be reduced. Additional steps include suppressing protein catabolism by providing calories via dextrose $10 \% .^{22}$ Arginine, L-carnitine or branched chain amino acids promote ammonia utilisation and therefore reduction of serum levels. ${ }^{26}$ Scavenging agents such as sodium phenylacetate and sodium phenylbutyrate can also promote degradation of ammonia through alternate pathways. ${ }^{15} 25$ Dialysis likewise aids in elimination of ammonia. Specifically for cerebral oedema associated with hyperammonemia, multiple therapies have been deployed with mixed success including hypothermia, $\mathrm{N}$-acetylcysteine and mannitol. ${ }^{15}$

To our knowledge, this is the first reported incident of hyperammonemia due to Ureaplasma infection in a CAR-T recipient. Owing to the immunosuppressed state of these individuals, along with potential impacts of CAR-T therapy on astrocytes, a high index of suspicion for these organisms is needed. Early 
Learning points

- Infection with urea-producing organisms (ie, Ureaplasma) can develop in immunocompromised patients, particularly recipients of organ and bone marrow transplantation, and present with sepsis and/or encephalopathy.

- Ureaplasma infection should be suspected in patients with hyperammonemia who do not have liver disease and who have a low likelihood of inborn errors of metabolism (ie, adult patients).

- If Ureaplasma infection is suspected, empirical antimicrobials should be started as detection of Ureaplasma requires Mycoplasma-specific media or PCR testing.

- Treatment of Ureaplasma requires macrolides, tetracyclines and/or fluoroquinolones along with multiple simultaneous interventions to reduce ammonia levels and the cerebral oedema that may develop.

empirical treatment, potentially with two antimicrobials, is necessary along with ammonia-lowering therapies. However, despite multipronged approaches, mortality remains high in similar populations and further research is needed regarding prevention and treatment of this complication. ${ }^{10}$

Contributors Both authors directly cared for the patient in the intensive care unit. PT wrote the manuscript and PA edited the manuscript.

Funding The authors have not declared a specific grant for this research from any funding agency in the public, commercial or not-for-profit sectors.

Competing interests None declared.

Patient consent for publication Obtained.

Provenance and peer review Not commissioned; externally peer reviewed.

Open access This is an open access article distributed in accordance with the Creative Commons Attribution Non Commercial (CC BY-NC 4.0) license, which permits others to distribute, remix, adapt, build upon this work non-commercially, and license their derivative works on different terms, provided the original work is properly cited and the use is non-commercial. See: http://creativecommons.org/ licenses/by-nc/4.0/.

ORCID iD

Pierre Tawfik http://orcid.org/0000-0003-4693-9163

\section{REFERENCES}

1 Wang Z, Wu Z, Liu Y, et al. New development in CAR-T cell therapy. J Hematol Oncol 2017;10:53.
2 Park JH, Rivière I, Gonen M, et al. Long-Term follow-up of CD19 CAR therapy in acute lymphoblastic leukemia. N Engl J Med Overseas Ed 2018;378:449-59.

3 Liu D, Zhao J. Cytokine release syndrome: grading, modeling, and new therapy. J Hematol Oncol 2018:11:121.

4 Lee DW, Santomasso BD, Locke FL, et al. ASTCT consensus grading for cytokine release syndrome and neurologic toxicity associated with immune effector cells. Biol Blood Marrow Transplant 2019;25:625-38.

5 Neelapu SS. Managing the toxicities of car T-cell therapy. Hematol Oncol 2019;37 Suppl 1:48-52.

6 Jhaveri VV, Lasalvia MT. Invasive Ureaplasma Infection in Patients Receiving Rituximab and Other Humoral Immunodeficiencies-A Case Report and Review of the Literature. Open Forum Infect Dis 2019;6:ofz399.

7 Espinós J, Rifón J, Pérez-Calvo J, et al. Idiopathic hyperammonemia following highdose chemotherapy. Bone Marrow Transplant 2006:37:899.

8 Cannon CA, Corcorran MA, Shaw KW, et al. Hyperammonemia syndrome due to Ureaplasma infection after liver-kidney transplant. Transp/ Infect Dis 2020;22:e13298

9 Legouy C, Hu A, Mochel F, et al. Ureaplasma parvum causes hyperammonemia presenting as refractory status epilepticus after kidney transplant. J Crit Care 2020;57:79-83.

10 Leger RF, Silverman MS, Hauck ES, et al. Hyperammonemia post lung transplantation: a review. Clin Med Insights Circ Respir Pulm Med 2020:14:117954842096623-7.

11 Davies SM, Szabo E, Wagner JE, et al. Idiopathic hyperammonemia: a frequently lethal complication of bone marrow transplantation. Bone Marrow Transplant 1996;17:1119-25.

12 Frere P, Canivet JL, Gennigens C, et al. Hyperammonemia after high-dose chemotherapy and stem cell transplantation. Bone Marrow Transplant 2000:26:343-5.

13 Graetz R, Meyer R, Shehab K, et al. Successful resolution of hyperammonemia following hematopoietic cell transplantation with directed treatment of Ureaplasma parvum infection. Transpl Infect Dis 2018;20:e12839.

14 Hyperammonemia [Internet]. StatPearls - National Library of Medicine. 2020.

15 Clay AS, Hainline BE. Hyperammonemia in the ICU. Chest 2007;132:1368-78.

16 Urea Cycle [Internet]. StatPearls - National Library of Medicine. 2020.

17 Gwee A, Curtis N. Ureaplasma - are you sitting comfortably? I Infect 2014;68:S19-23.

18 Shah S. Ureaplasma urealyticum. 5 ed. Elsevier, 2018.

19 Paparoupa M, Barten MJ, de Heer J, et al. Hyperammonemia by Ureaplasma urealyticum pneumonia after lung transplantation. Respir Med Case Rep 2020;30:101080

20 Buckingham SC, Crouse DT, Knapp KM, et al. Pneumonitis associated with Ureaplasma urealyticum in children with cancer. Clin Infect Dis 2003;36:225-8.

21 Yan J, Li S, Li S. The role of the liver in sepsis. Int Rev Immunol 2014:33:498-510.

22 Gust J, Finney OC, Li D, et al. Glial injury in neurotoxicity after pediatric CD19-directed chimeric antigen receptor T cell therapy. Ann Neurol 2019;86:42-54.

23 Urea Cycle Disorders [Internet]. StatPearls - National Library of Medicine. 2020.

24 Ferreira CR, van Karnebeek CDM. Inborn errors of metabolism. Handb Clin Neurol 2019;162:449-81.

25 Matoori S, Leroux J-C. Recent advances in the treatment of hyperammonemia. Adv Drug Deliv Rev 2015;90:55-68.

26 Liu J, Lkhagva E, Chung $\mathrm{H}-$, et al. The Pharmabiotic approach to treat hyperammonemia. Nutrients 2018;10:140.

Copyright 2021 BMJ Publishing Group. All rights reserved. For permission to reuse any of this content visit

https://www.bmj.com/company/products-services/rights-and-licensing/permissions/

BMJ Case Report Fellows may re-use this article for personal use and teaching without any further permission.

Become a Fellow of BMJ Case Reports today and you can:

- Submit as many cases as you like

- Enjoy fast sympathetic peer review and rapid publication of accepted articles

- Access all the published articles

- Re-use any of the published material for personal use and teaching without further permission

Customer Service

If you have any further queries about your subscription, please contact our customer services team on +44 (0) 2071111105 or via email at support@bmj.com.

Visit casereports.bmj.com for more articles like this and to become a Fellow 